\title{
Application of Selected Malaysian Wild Plant Leaves as Potential Control of Cyanobacterial Bloom
}

\author{
Tengku Nadiah Yusof ${ }^{a}$, Mohd. Rafatullah ${ }^{a, *}$, Norli Ismail ${ }^{a}, Z_{\text {Zarina Zainuddin }}$, \\ Japareng Lalung ${ }^{a, *}$
}

\author{
${ }^{a}$ School of Industrial Technology, Universiti Sains Malaysia, 11800, Pulau Penang, Malaysia \\ ${ }^{b}$ Department of Biotechnology, International Islamic University Malaysia, Jalan Sultan Ahmad Shah, \\ 25200 Kuantan, Pahang, Malaysia
}

\begin{abstract}
Efficient cyanobacterial bloom management is important because a bloom in a water body may cause problems such as unpleasant odour and taste, and most importantly, toxin production that are potentially fatal to human and animals. Previous researches have shown that various aquatic and terrestrial plants, especially traditional herbs and shrubs, were able to inhibit the growth of cyanobacteria; the most common plant used to control cyanobacterial growth is barley straw. Therefore, if any wild terrestrial leaf can perform the same control, it would provide a low cost and environmental friendly alternative of cyanobacterial management. In this study, $10 \mathrm{~g} / \mathrm{L}$ of ten different species of terrestrial wild plant leaves leachates from Penang, Malaysia were individually tested for their abilities to inhibit the growth of eight isolated cyanobacteria namely Microcystis sp., Pseudoanabaena sp., Planktothrix sp., Limnothrix sp., Ocsillatoria sp., Synecocystis sp. and two Synechococcus spp. for 15 days. The results showed that most leaves effectively controlled all cyanobacterial growth but at different rates, depending on the species of cyanobacteria and the species of plant leaves used. The outcomes suggest that the wild plant terrestrial leaves released effective anti-cyanobacterial substances, giving new insight to terrestrial leaves as natural biological controls of cyanobacterial bloom.
\end{abstract}

Keywords: Algae, Biological control, Cyanobacteria, Plant, water body

\section{INTRODUCTION}

Cyanobacteria or also known as blue-green algae are prokaryotes with unique characteristics. Unlike other prokaryotes, cyanobacteria contain chlorophyll that enables them to obtain their nutrients mainly through photosynthetic action, making them important to provide oxygen in the water environment. However, excessive growth of cyanobacteria leads to the formation of visible cyanobacteria, or cyanobacterial blooms, and can cause several problems such as unpleasant odour and taste, and most importantly, toxin production[1].

Consumption or direct contact of cyanobacterial toxins can lead to severe health consequences. For instance, hepatotoxic microcystin was the cause of death of 60 dialysis patients in Brazil[2] and cylindrospermopsin has led to the hospitalisation of 148 children in Palm Island, Australia[3]. Currently, toxic cyanobacteria can be detected in more than 65 countries, including Thailand[4], Singapore[5], and Malaysia, which has confirmed the presence of toxic cyanobacteria in 2015 [6].

Increasing concern on harmful and unpleasant cyanobacteria blooming in the freshwater environment leads to extensive researches on cyanobacterial growth control. Currently, the most widely used chemical for water treatment, copper (II) sulphate $\left(\mathrm{CuSO}_{4}\right)$ has harmed a wide spectrum of species, risking a secondary pollution in the water environment[7]. While physical treatments such as sedimentation has lowered the secondary pollution risk, the treatments can injure other organisms and are usually energy consuming and expensive[7]. Hence, more scientists are in search of biologicalderived treatments as an alternative.

In general, ideal anti-cyanobacterial compounds are characterized by a strong inhibition to cyanobacteria and is non-toxic to other organisms, readily degraded in the environment, inexpensive and safe to the environment[7].The effectiveness of the compounds which is influenced by hydrophilicity and hydrophobicity is also one of the important characteristics [8]. In addition, ideally, an anti-cyanobacterial compound should be able to inhibit most cyanobacterial species. If the inhibition is species specific, the compound may enhance the growth of other cyanobacterial species, which is undesirable if the enhanced cyanobacterial species are a toxin-producing species [9]. 
Currently, most researches focuses on an anti-cyanobacterial compound derived from waste and plant biomass, and so far, the most effective and researched cyanobacterial bio-control is barley straw. However, researchers argue on the likelihood of its long-term effects on the ecosystem due to unnatural input of the waste biomass unto environment[10]. This thus leads to one of the earliest researches on anti-cyanobacterial compounds using a more natural resource; deciduous plant leaves[10]. Subsequently, more researchers observed the inhibition of cyanobacterial growth by different terrestrial plants and herbs, such as Gingko biloba[11],oak trees[12], Chinese herbs[13], andaquatic plants such as Myriophyllum spicatum[14],Pista stratiotes [15] and Hydrilla verticillata [16].Several active compounds released from plants have been successfully isolated and characterized in previous researches, which include polyphenol[17],terpenoid[8] and fatty acid[14]. These compounds inhibit growth via different pathways, such as inhibition of photosynthesis, disruption of cellular structure, and inactivation of enzymatic and non-enzymatic functions [17].

All the past researches conducted showed that plant leaves released anti-cyanobacterial compounds. Therefore, we could hypothesize that in natural environment, leaf litter of wild terrestrial plants around lakes or reservoirs leaches compounds are able to inhibit the growth of cyanobacteria. Consequently, this provides a low cost and environmental friendly alternative method on bloom management. However, leaves may also release organic carbon and nutrients that could enhance cyanobacterial growth[18]. As such, the effects of dry leaves to cyanobacterial growth in the natural environment are not fully known.

This study was conducted to examine the potential of terrestrial leaves as a natural cyanobacterial control management by using ten individually terrestrial plants on eight isolated cyanobacteria species, including toxic Microcystis sp. that was successfully isolated from Penang, Malaysia.

\section{Materials AND Methods}

\subsection{Materials}

Cyanobacterial species were collected and identified from Dr. Japareng's laboratory, School of Industrial Technology, Universiti Sains Malaysia (USM), Penang, Malaysia. Eight isolated cyanobacterial species were selected:Synechococcus sp., Synecocystis sp. and Planktothrix sp. isolated from Teluk Bahang (TB) dam, Penang, Malaysia;Pseudoanabaena sp. and Synechococcus sp. isolated from Ayer Itam (AI) reservoir, Penang Malaysia;Limnothrix sp., isolated from Mengkuang dam, Penang Malaysia;Oscillatoria sp. from Teluk Intan, Perak, Malaysia; and toxic Microcystis sp., isolated from Tasik Harapan Lake, USM (Figure 1). All species were cultured and maintained in BG 11 liquid media.

Ten plant leaves were collected and identified by the Biological School of USM. The selected leaves tested for their abilities to inhibit cyanobacterial growth were: Andira inermis, Millettia pinnata, Mesua ferrea, Carbera odollam, Kopsia fruticosa, Morinda elliptica, Syzygium campanulatum, Clitoria fairchildiana, Polyalthia longifolia and Millettia atropurpurea.
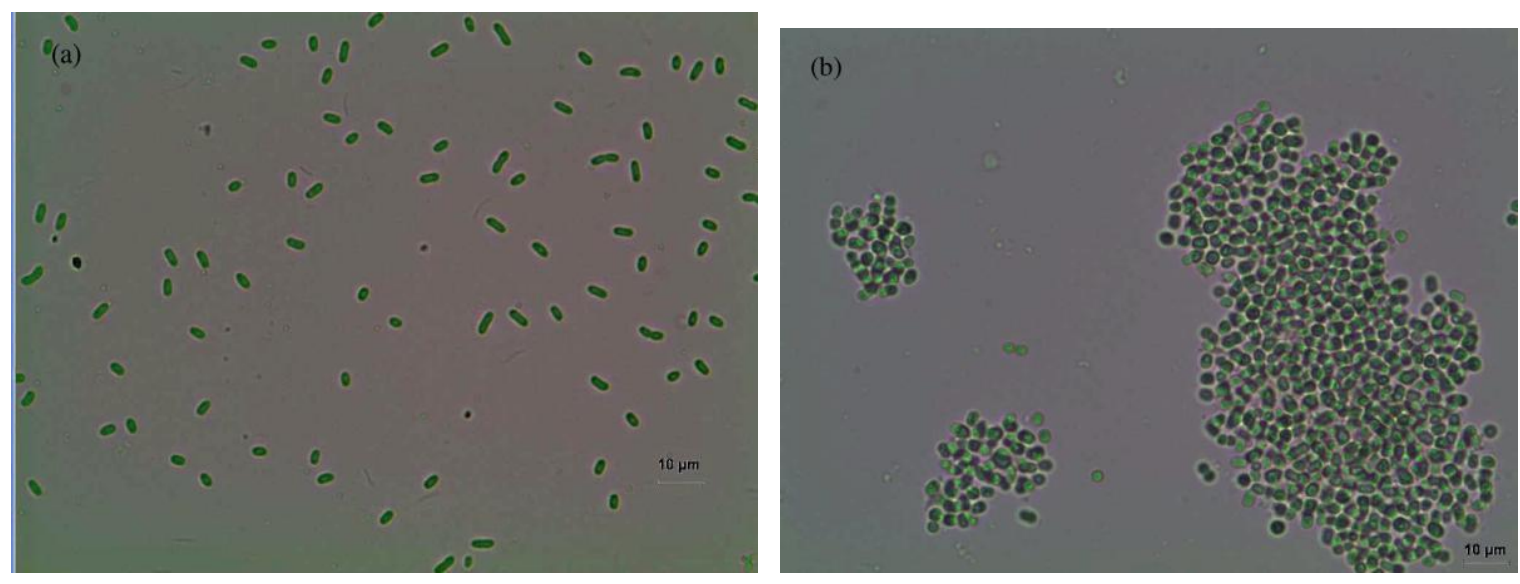


\section{Application of Selected Malaysian Wild Plant Leaves as Potential Control of Cyanobacterial Bloom}

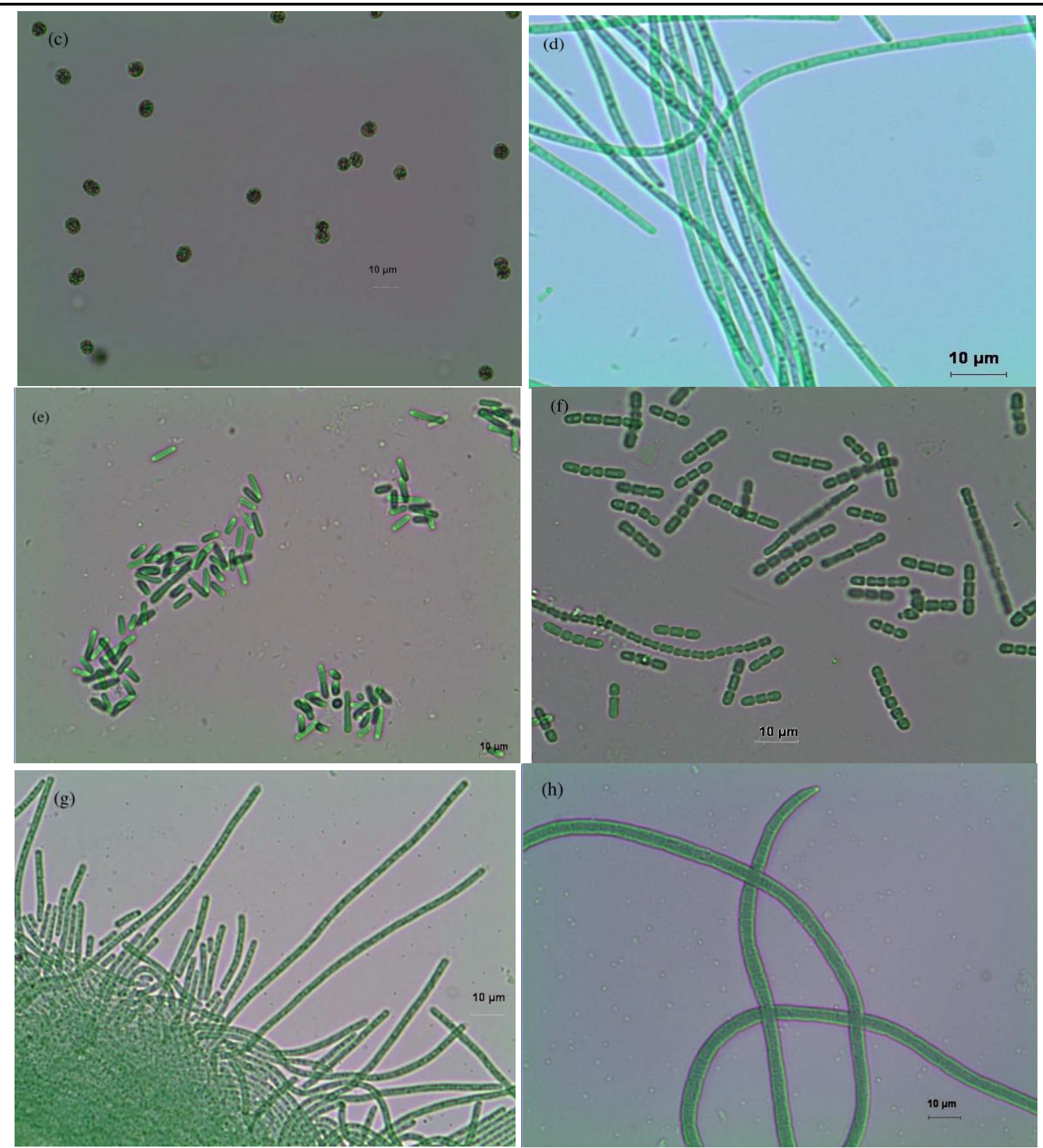

Figure1. Cyanobacteria species used in the studies a) Synechococcus sp. isolated from Teluk Bahang (TB) dam, Penang b) Synechocystis sp. c) Microcystis sp. isolated from Ayer Itam dam, Penang d) Planktothrix sp. isolated from Teluk Bahang e) Synechococcus sp. isolated from Ayer Itam (AI) dam f) Pseudoanabaena sp. isolated from Ayer Itam dam g) Limnothrix sp. isolated from Mengkuang dam, Penang h) Ocsilatoria sp. from Teluk Intan, Perak.

\subsection{Maintenance of Cyanobacteria}

All cyanobacterial species were maintained in a $250 \mathrm{~mL}$ conical flask (Fisher) containing $100 \mathrm{~mL}$ of autoclaved liquid BG 11 culture medium. Each flask was sealed with cotton wool bungs whilst allowing aeration. The cultures were placed under continuous light condition on an incubation shaker at $95 \mathrm{rpm}$ at room temperature. For each subculture, $1-2 \mathrm{~mL}$ of the previous culture, depending on the density was added into a new medium.

\subsection{Bioassays}

\subsubsection{Cyanobacterial Growth Assays}

Growth assays of each cyanobacterial species were conducted by transferring $100-200 \mu \mathrm{L}$ of cyanobacterial culture onto an autoclaved $28 \mathrm{ml}$ of Universal bottle (Favorit) containing $10 \mathrm{~mL}$ of BG 11 liquid media. The bottle was then loosely capped to allow aeration. The assays were conducted in triplicate under continous light at room temperature and shaken constantly at $95 \mathrm{rpm}$ using an incubator shaker for 15 days. Cyanobacterial growth were measured by taking chlorophyll $a$ value on day 7 and day 15. 


\subsubsection{Leaf Leachate Preparation}

The leaf leachate of each terrestrial plantwas prepared by drying the freshly collected leaves under direct sunlight for two weeks. $1 \mathrm{~g}$ of small cut $(<1 \mathrm{~cm} \mathrm{x} 1 \mathrm{~cm})$ dried plant leaf was transferred into $250 \mathrm{~mL}$ conical flask containing sterile $100 \mathrm{~mL}$ BG 11 medium. The leaf compounds were allowed to leach into the medium for 7 days at room condition before the leaf leachates bioassays were conducted.

\subsubsection{Leaf Leachate Bioassays}

Anti-cyanobacterial activity for each leaf was observed by aseptically transferring $10 \mathrm{~mL}$ BG 11 media containing leaf leachate into a sterile $28 \mathrm{~mL}$ universal bottle. Depending on the cell density, $100-200 \mu \mathrm{L}$ cyanobacterial stock culture were added into the bottle. The bottle was then capped loosely for aeration. Each leaf bioassay was conducted in triplicates under a controlled-environment cabinet at room temperature $\left(28^{\circ} \mathrm{C}\right)$ under white fluorescence light. The culture bottles were shaken constantly at $95 \mathrm{rpm}$ for 15 days. For each replicate, $1 \mathrm{~mL}$ of culture was taken on day 7 and 15 of incubation for chlorophyll $a$ extraction.

\subsection{Cyanobacterial Growth Measurement}

Cyanobacterial growth was measured based on the concentration of chlorophyll $a$. For the extraction of chlorophyll $a$ for each cell harvest, $1 \mathrm{~mL}$ of cell culture was centrifuged for 2 minutes at 10,000 rpm (Eppendorf). Then, $0.5 \mathrm{~mL}$ of supernatant was removed. The remaining sample was further centrifuged for 2 minutes at the same speed. Afterwards, the rest of the supernatant was completely removed. Chlorophyll $a$ reading was taken by re-suspending harvested cells in $1 \mathrm{~mL}$ of $90 \%$ methanol containing $10 \mathrm{mg} / \mathrm{L}$ magnesium carbonate $\left(\mathrm{MgCO}_{3}\right)$ and incubated for 1 hour at room temperature in the dark. After the incubation, extracted chlorophyll $a$ was centrifuged for 5 minutes at 10,000 rpm. The absorbance of the supernatant was measured at $665 \mathrm{~nm}$ using a UV-Visible Spectrophotometer (Shimadzu) and $90 \%$ methanol containing $10 \mathrm{mg} / \mathrm{L}$ of $\mathrm{MgCO}_{3}$ which acts as a reference blank. The chlorophyll $a$ content was calculated using the following formula:

$$
\text { Chlorophyll } a \text { content }(\mathrm{mg} / \mathrm{L})=\mathrm{OD}_{665} \times 12.9447
$$

Where $\mathrm{OD}_{665}=$ absorbance at $665 \mathrm{~nm}$, and $12.9447=$ constant

\subsection{Inhibition Efficiency}

Chlorophyll $a$ data were collected and the inhibition efficiency (\%) of leaf leachates was analysed based on the following formula:

$$
\text { Inhibition efficiency }(\%)=[(\text { Control }- \text { Treatment }) / \text { Control }] \times 100
$$

Where control = chlorophyll $a$ value of cyanobacteria growth assay in BG 11 without leaf leachates, treatment $=$ chlorophyll $a$ value of cyanobacterial growth bioassay in BG 11 with leaf leachates.

\subsection{Statistical Analysis}

Univariate analysis of two-way ANOVA was conducted to analyse and compare the inhibition efficiency of two factors: cyanobacteria species and plant species on 15 days of culture. Tukey HSD's test was conducted to analyse homogeneity between species. Statistical data was conducted using IBM SPSS statistic version 22.

\section{RESUlTS AND DISCUSSION}

\subsection{Growth Inhibition of Cyanobacteria by the Leaf Leachates}

The effect of leaf leachates in the media on each eight isolated cyanobacteria species were observed by comparing and analysing the cyanobacterial growth rate in the absence and presence of leaf leachates in the medium. Bioassays were conducted in triplicate at room temperature under constant shaking and light. Cyanobacterial growth was recorded based on the chlorophyll $a$ concentration taken on day 7 and day 15. From the data collected, the inhibition efficiency was calculated (Table 1). 


\section{Application of Selected Malaysian Wild Plant Leaves as Potential Control of Cyanobacterial Bloom}

Table1. The effect of ten individually leaf leachate in the BG 11 liquid media on the growth of eight cyanobacterial species was observed by calculating algal-inhibition efficiency (\%) on day 7 and day 15 of incubation. Efficiency inhibition $(\%)$ were calculated based on formula $=($ Control - Treatment $) /$ Control $\times 100$; where control was the chlorophyll a content of cyanobacteria cultured on BG 11 media absence of leaf leachates. Whilst treatment was the chlorophyll a value of cyanobacteria incubated in BG 11 containing leaf leachates. All Bioassays were conducted in triplicate at constant room conditions.

\begin{tabular}{|c|c|c|c|}
\hline \multirow[t]{2}{*}{ Plant species } & \multirow[t]{2}{*}{ Cyanobacteria } & \multicolumn{2}{|c|}{ Inhibition Efficiency (\%) mean $\pm \mathrm{SD}^{\mathrm{a}}$} \\
\hline & & Day 7 & Day 15 \\
\hline \multirow{8}{*}{ Andirainermis } & Limnothrix sp. & $74.6 \pm 2.1$ & $78.91 \pm 3.9$ \\
\hline & Microcystis sp. & $38.3 \pm 6.8$ & $73.58 \pm 1.8$ \\
\hline & Ocsillatoria sp. & $54.5 \pm 6.0$ & $74.7 \pm 1.7$ \\
\hline & Planktothrix sp. & $70.5 \pm 0.6$ & $82.2 \pm 2.6$ \\
\hline & Pseudoanabaena sp. & $18.7 \pm 1.2$ & $45.0 \pm 3.2$ \\
\hline & Synechococcus sp. (AI) & $30.6 \pm 0.9$ & $81.6 \pm 3.4$ \\
\hline & Synechococcus sp. (TB) & $64.4 \pm 3.8$ & $80.8 \pm 1.5$ \\
\hline & Synechocystis sp. & $18.0 \pm 7.1$ & $67.9 \pm 0.7$ \\
\hline \multirow{8}{*}{ Carberaodollam } & Limnothrix sp. & $67.4 \pm 9.6$ & $80.0 \pm 3.9$ \\
\hline & Microcystis sp. & $34.0 \pm 5.1$ & $74.0 \pm 0.5$ \\
\hline & Ocsillatoria $\mathrm{sp}$. & $42.5 \pm 3.7$ & $72.3 \pm 1.2$ \\
\hline & Planktothrix sp. & $75.2 \pm 2.3$ & $82.9 \pm 5.1$ \\
\hline & Pseudoanabaena sp. & $16.2 \pm 0.70$ & $43.2 \pm 3.6$ \\
\hline & Synechococcus sp.(AI) & $41.8 \pm 1.9$ & $85.8 \pm 0.1$ \\
\hline & Synechococcus sp.(TB) & $72.3 \pm 2.9$ & $87.7 \pm 1.2$ \\
\hline & Synechocystis sp. & $19.8 \pm 5.6$ & $72.0 \pm 0.6$ \\
\hline \multirow[t]{8}{*}{ Clitoriafairchildiana } & Limnothrix sp. & $77.9 \pm 6.7$ & $80.5 \pm 1.2$ \\
\hline & Microcystis sp. & $41.4 \pm 10.5$ & $70.5 \pm 4.6$ \\
\hline & Ocsillatoria sp. & $29.3 \pm 33.9$ & $73.1 \pm 13.4$ \\
\hline & Planktothrix sp. & $65.9 \pm 5.3$ & $78.3 \pm 1.7$ \\
\hline & Pseudoanabaena sp. & $20.95 \pm 2.4$ & $42.9 \pm 10.0$ \\
\hline & Synechococcus sp.(AI) & $40.0 \pm 12.6$ & $83.7 \pm 1.5$ \\
\hline & Synechococcus sp.(TB) & $75.0 \pm 3.3$ & $87.5 \pm 2.9$ \\
\hline & Synechocystis sp. & $-9.9 \pm 53.3$ & $60.4 \pm 9.8$ \\
\hline \multirow{8}{*}{ Kopsiafruticosa } & Limnothrix sp. & $77.2 \pm 1.8$ & $78.1 \pm 4.5$ \\
\hline & Microcystis sp. & $51.9 \pm 7.2$ & $70.0 \pm 1.5$ \\
\hline & Ocsillatoria sp. & $62.3 \pm 7.5$ & $83.7 \pm 1.0$ \\
\hline & Planktothrix sp. & $80.8 \pm 2.1$ & $85.8 \pm 0.7$ \\
\hline & Pseudoanabaena sp. & $32.4 \pm 2.3$ & $42.6 \pm 3.2$ \\
\hline & Synechococcus sp.(AI) & $55.7 \pm 5.1$ & $86.4 \pm 0.3$ \\
\hline & Synechococcus sp.(TB) & $79.0 \pm 2.5$ & $90.3 \pm 0.4$ \\
\hline & Synechocystis sp. & $44.1 \pm 4.5$ & $73.6 \pm 4.4$ \\
\hline \multirow[t]{8}{*}{ Mesuaferrea } & Limnothrix sp. & $67.6 \pm 4.2$ & $68.7 \pm 6.2$ \\
\hline & Microcystis sp. & $46.8 \pm 4.5$ & $67.7 \pm 4.4$ \\
\hline & Ocsillatoria sp. & $28.3 \pm 16.2$ & $55.8 \pm 13.0$ \\
\hline & Planktothrix sp. & $71.0 \pm 7.7$ & $67.7 \pm 7.4$ \\
\hline & Pseudoanabaena sp. & $-21.8 \pm 2.43$ & $-36.4 \pm 15.7$ \\
\hline & Synechococcus sp.(AI) & $12.4 \pm 12.8$ & $59.1 \pm 3.6$ \\
\hline & Synechococcus sp.(TB) & $51.8 \pm 9.6$ & $61.0 \pm 4.0$ \\
\hline & Synechocystis sp. & $26.1 \pm 6.3$ & $33.8 \pm 5.7$ \\
\hline \multirow[t]{8}{*}{ Millettiaatropurpurea } & Limnothrix sp. & $77.7 \pm 6.4$ & $78.6 \pm 2.6$ \\
\hline & Microcystis sp. & $46.6 \pm 10.9$ & $78.1 \pm 5.0$ \\
\hline & Ocsillatoria sp. & $52.0 \pm 4.4$ & $81.3 \pm 3.4$ \\
\hline & Planktothrix sp. & $62.3 \pm 7.1$ & $54.1 \pm 3.5$ \\
\hline & Pseudoanabaena sp. & $16.48 \pm 2.4$ & $15.8 \pm 21.4$ \\
\hline & Synechococcus sp.(AI) & $31.9 \pm 13.2$ & $73.2 \pm 8.4$ \\
\hline & Synechococcus sp.(TB) & $72.8 \pm 5.4$ & $86.1 \pm 5.3$ \\
\hline & Synechocystis sp. & $10.2 \pm 20.9$ & $47.6 \pm 11.1$ \\
\hline \multirow[t]{3}{*}{ Millettiapinnata } & Limnothrix sp. & $79.2 \pm 1.8$ & $86.8 \pm 1.7$ \\
\hline & Microcystis sp. & $46.6 \pm 3.0$ & $83.6 \pm 1.1$ \\
\hline & Ocsillatoria $\mathrm{sp}$. & $71.3 \pm 3.3$ & $91.3 \pm 0.9$ \\
\hline
\end{tabular}


Tengku Nadiah Yusof et al.

\begin{tabular}{|c|c|c|c|}
\hline & Planktothrix sp. & $73.6 \pm 4.2$ & $85.8 \pm 4.8$ \\
\hline & Pseudoanabaena sp. & $40.2 \pm 7.60$ & $65.5 \pm 3.0$ \\
\hline & Synechococcus sp. (AI) & $52.4 \pm 9.6$ & $90.9 \pm 0.7$ \\
\hline & Synechococcus sp. (TB) & $71.1 \pm 0.3$ & $88.1 \pm 2.3$ \\
\hline & Synechocystis sp. & $35.0 \pm 16.4$ & $84.1 \pm 2.5$ \\
\hline Morindaelliptica & Limnothrix sp. & $77.6 \pm 2.7$ & $87.8 \pm 0.4$ \\
\hline & Microcystis sp. & $49.6 \pm 0.6$ & $82.5 \pm 0.8$ \\
\hline & Ocsillatoria $\mathrm{sp}$. & $58.2 \pm 6.3$ & $91.7 \pm 0.3$ \\
\hline & Planktothrix sp. & $75.7 \pm 3.0$ & $90.7 \pm 0.9$ \\
\hline & Pseudoanabaena sp. & $29.6 \pm 2.1$ & $67.0 \pm 1.5$ \\
\hline & Synechococcus sp.(AI) & $30.4 \pm 4.7$ & $79.4 \pm 5.2$ \\
\hline & Synechococcus sp.(TB) & $74.9 \pm 0.8$ & $86.9 \pm 0.7$ \\
\hline & Synechocystis sp. & $34.5 \pm 1.8$ & $83.4 \pm 0.7$ \\
\hline Polyalthialongifolia & Limnothrix sp. & $75.7 \pm 4.7$ & $78.3 \pm 1.7$ \\
\hline & Microcystis $\mathrm{sp}$. & $38.1 \pm 3.3$ & $74.2 \pm 2.3$ \\
\hline & Ocsillatoria sp. & $31.6 \pm 7.2$ & $85.3 \pm 2.6$ \\
\hline & Planktothrix sp. & $64.7 \pm 3.3$ & $61.0 \pm 1.0$ \\
\hline & Pseudoanabaena sp. & $31.28 \pm 0.7$ & $38.7 \pm 11.6$ \\
\hline & Synechococcus sp.(AI) & $5.8 \pm 8.2$ & $33.8 \pm 3.7$ \\
\hline & Synechococcus sp. TB & $58.0 \pm 6.5$ & $45.8 \pm 2.8$ \\
\hline & Synechocystis & $18.8 \pm 10.4$ & $30.5 \pm 5.1$ \\
\hline Syzygiumcampanulatum & Limnothrix sp. & $81.3 \pm 1.5$ & $86.6 \pm 1.6$ \\
\hline & Microcystis $\mathrm{sp}$. & $51.9 \pm 2.7$ & $83.3 \pm 0.4$ \\
\hline & Ocsillatoria $\mathrm{sp}$. & $65.4 \pm 4.2$ & $90.9 \pm 1.5$ \\
\hline & Planktothrix sp. & $79.0 \pm 0.8$ & $89.8 \pm 0.2$ \\
\hline & Pseudoanabaena sp. & $17.32 \pm 7.6$ & $65.3 \pm 1.3$ \\
\hline & Synechococcus sp.(AI) & $39.5 \pm 9.6$ & $89.4 \pm 0.5$ \\
\hline & Synechococcus sp.(TB) & $81.0 \pm 0.6$ & $94.1 \pm 0.3$ \\
\hline & Synechocystis sp. & $39.7 \pm 2.8$ & $82.4 \pm 0.3$ \\
\hline
\end{tabular}

${ }^{a}$ Standard deviation of mean

On day 7, growth inhibition of cyanobacteria by most leaf leachates were low, especially on five isolates; Microcystis sp., ynechoccoccus sp. Ayer Itam isolation (AI), Synechocystis sp., Ocsillatoria sp. and Pseudoanabaena sp. In addition, cyanobacteria Synechocystis sp., and Pseudoanabaena sp.. In addition, cyanobacteria Synechocystissp., and Pseudoana- baenasp. growth were enhanced in media containing $C$. fairchildiana and $M$. ferrea leaf leachates respectively. The result may be likely due to the release of nutrients and organic compounds from plants leaves, which balances with anticyanobacterial compounds, resulting in growth enhancement in a few cases and low inhibition efficiency.

On the other hand, after 15 days of incubation, all leaf leachates were generally able to inhibit the growth of cyanobacteria, except Pseudoanabaena sp., which has high resistance to most leaf leachates and were enhance in media containing $M$. ferrea leaf leachates. It was also observed that $M$. ferrea as well as $P$. longifolia leaves have a lower ability to inhibit the growth of most cyanobacteria species compared to other plant leaves. However, it should be noted that all leaf leachates were able to effectively inhibit the growth of toxic Microcystis sp., which is an important cyanobacterium to be controlled for bloom management. The results indicating that anti-cyanobacterial compounds released from the leaves may have counteract nutrients and organic compounds, thus successfully controlled the cyanobacterial growth.

The outcomes are similar to many previous researches that showed the release of anti-cyanobacterial compounds from plants. However, the study on the isolation of specific compounds and an understanding of its mechanisms are limited due to high workload and complexity in separation and characterization of plants compounds[19]. In 2014, a research group has successfully isolated and proved that 2 compounds under the group of flavonolignin namely salcolin a and salcolin $b$ from barley straw, were algistatic and algicidal towards cyanobacteria respectively[19]. It is possible that salcolina andsalcolin b compounds play a vital role as anti-cyanobacterial in this study. Hence further research on the presence of salcolina and salcolin $b$ in plants should be conducted in the future using compounds separation. 


\subsection{Statistical Analysis}

A two-way ANOVA analysis on the day 15 data collected was conducted to analyze and compare the interaction between the ten different leaf leachates on the 8 cyanobacterial species. The statistical analysis was summarized in Table 2.

Table2. The two-way ANOVA results for inhibition efficiency on day 15 showed that each factors and interaction $p<0.0001$, indicating each factors and the interactions has significant effect on inhibition efficiency.

\begin{tabular}{|c|c|c|c|c|c|}
\hline Source & Type III Sum of Squares & df & Mean Square & F & Sig. \\
\hline Plant species & 34244.536 & 9 & 3804.948 & 139.314 & .000 \\
\hline Cyanobacteria & 43273.080 & 7 & 6181.869 & 226.342 & .000 \\
\hline Plant species * Cyanobacteria & 26148.275 & 63 & 415.052 & 15.197 & .000 \\
\hline Error & 4369.940 & 160 & 27.312 & & \\
\hline Total & 1342598.430 & 240 & & & \\
\hline
\end{tabular}

The $p$-value of the two factors and the interaction are $p<0.0001$, indicating that growth inhibition differed considerably depending on both the cyanobacterial species and plants. Thus indicates that different cyanobacterial species have different sensitivities towards anti-algae compounds released and that plant species were likely to release different compounds at different concentrations. To examine the significant differences between each factor, Tukey's HSD test was also conducted (Table $3)$.

Table3. Tukey's HSD were conducted to examine homogeneity of each factors based on mean: (a) Cyanobacterial species, (b) Plant species

(a)

\begin{tabular}{|l|c|c|c|c|c|c|}
\hline \multirow{2}{*}{ Cyanobacteria } & \multirow{2}{*}{$\mathrm{N}$} & \multicolumn{5}{c|}{ Subset } \\
\cline { 3 - 7 } & & 1 & 2 & 3 & 4 & 5 \\
\hline Pseudoanabaena sp. & 30 & 38.9699 & & & & \\
\hline Synechocystis sp. & 30 & & 63.5657 & & & \\
\hline Microcystis sp. & 30 & & & 75.758 & & \\
\hline Synechococcus sp.(AI) & 30 & & & 76.3283 & 76.3283 & \\
\hline Planktothrix sp. & 30 & & & 77.8256 & 77.8256 & 77.8256 \\
\hline Ocsillatoria sp. & 30 & & & & 80.0435 & 80.0435 \\
\hline Limnothrix sp. & 30 & & & & 80.4343 & 80.4343 \\
\hline Synechococcus sp.(TB) & 30 & & & & & 80.8487 \\
\hline Sig. & & 1 & 1 & 0.789 & 0.054 & 0.334 \\
\hline
\end{tabular}

The error term is Mean Square (Error) $=27.312$.

(b)

\begin{tabular}{|c|c|c|c|c|c|c|}
\hline \multirow{2}{*}{ Plant species } & \multirow{2}{*}{$\mathrm{N}$} & \multicolumn{5}{|c|}{ Subset } \\
\hline & & 1 & 2 & 3 & 4 & 5 \\
\hline M. ferrea & 24 & 47.17991 & & & & \\
\hline P. longifolia & 24 & & 55.93884 & & & \\
\hline M. atropurpurea & 24 & & & 64.38219 & & \\
\hline C. fairchildiana & 24 & & & & 72.11865 & \\
\hline A. inermis & 24 & & & & 73.08782 & \\
\hline C. odollam & 24 & & & & 74.75297 & \\
\hline K. fruticosa & 24 & & & & 76.33339 & \\
\hline M. elliptica & 24 & & & & & 83.68019 \\
\hline M. pinnata & 24 & & & & & 84.51668 \\
\hline S. campanulatum & 24 & & & & & 85.22696 \\
\hline Sig. & & 1.000 & 1.000 & 1.000 & .148 & .990 \\
\hline
\end{tabular}

The error term is Mean Square (Error) $=27.312$.

Based on statistical analysis, M. ferrea, followed by P. Longifolia and M. atropurpurea have a low cyanobacterial growth inhibition efficiency mean compared to other leaf leachates, while M. elliptica, $M$. Pinnata and $S$. campanulatum leaf leachates have a high inhibition efficiency. However, cyanobacteria Pseudoanabaena sp., followed by Synechocystis sp.have a high resistance towards plant leaf leachates and Synechococcus sp. isolated from Teluk Bahang was the most sensitive to the treatments. 


\subsection{Leaf Leachate Preparation}

Generally terrestrial leaves have a thick cuticle, making the release of an active compound harder[18]. Therefore, fresh leaves collected were dried under direct sunlight for two weeks to allow the destruction of the leaves' cuticle and subsequently increase the rate of active compound released. The individually dry leaf water-soluble compounds were allowed to leach into BG 11 liquid media for 7 days before the media liquid was used to cultivate cyanobacteria.

In this study, leaves were dried under natural environment and the high boiling of leaves or autoclaving was omitted as it may lead to the loss of volatile anti-cyanobacterial compounds. In addition, the aim of this experiment was to observe potential of dry leaves as a natural bio-control of cyanobacteria in the actual environment. Thus, autoclaving was not practical. From the results table (Table 1) on day 15, a high growth inhibition by a non-autoclaved leaf was observed, similar to researches using bananas and oranges[20] and barley straw as bio-controls[9]. Previous researches have also confirmed that high boiling will lead to the destruction of plant-derived active compounds, as depicted in the example of the Armesia annua-derived compound, artemisinin, as a malaria treatment[21] which was later studied as an anti-algae compound[22]. However, the outcomes contrasted to previous research on the deciduous leaf, where autoclaving was required to extract leaves compound for effective cyanobacterial inhibition[10]. Therefore, further evaluation on high boiling or autoclaving of plant leaves is required.

\subsection{Wild Plant Leaves as Potential Control of Cyanobacterial Bloom}

Although the study showed a high inhibition effect of the leaves leachates to cyanobacterial growth, inhibition activity may change with environmental conditions, such as temperature, water, photoperiod, and research methodology, such as initial concentration, sun exposure and maturity of plant leaves[23].Therefore, a laboratory scale experiment may not reflect the actual environment. It is however interesting to note thatno severe cyanobacterial blooms were observed in 2014 to 2015 in Ayer Itam reservoir, Mengkuang and Teluk Bahang dam, Penang, Malaysia, eventhough as a tropical country, cyanobacterial blooms possibly occurred all year round due to favourable light intensity and temperature for cyanobacterial growth [24].The reservoirs from where the cyanobacteria were isolated are situated far from industrialized area and are surrounded by forest trees. From the observation, fallen leaves from the forest trees may potentially play a role in inhibiting cyanobacterial bloom formation. Thus, based on results from this study, this strengthens the theory that fallen dry leaves acts as a natural cyanobacterial bloom management.

However, the dynamics of cyanobacterial population in an environment involves many factors and is yet to be fully understood[25]. In addition, using biological-derived substances for cyanobacterial bloom management may raise other concerns, such as weak inhibitory effect, emerging anticyanobacterial compound resistance in a population pool and the release of toxins during bloom collapse[7]. Besides that, as observed in this study, cyanobacterial growth inhibition is dependent on cyanobacterial and plant species. As such, a specific cyanobacterial species may be enhanced by certain plant leaves, but inhibited by other plant leaves, and vice versa. Nevertheless, by planting various species of terrestrial leaves surround the water-bodies, a variety of cyanobacterial species can be controlled and an early prevention of cyanobacterial bloom is able to prevent release of toxins due to bloom collapse.

Overall, leaves can inhibit the growth of cyanobacteria and act as natural bio-control of cyanobacteria. For future direction, research should also be conducted at an environmental scale, as the laboratory scale is too simple to reflect actual circumstances. Evaluation of toxicity of the compounds to other organisms should be also conducted and further evaluations on the active compound of anticyanobacteria using a fractionated technique such as HPLC, NMR or GC-MS for further understanding on the molecules and mechanisms is required

\section{Conclusions}

Based on the experimentation results, it can be seen that leaves are able to inhibit the growth of cyanobacteria, indicating release of an anti-cyanobacterial compound. However, inhibition efficiency depended on the cyanobacterial and plant species. Overall, the outcomes give new insight to terrestrial leaves as natural biological controls of cyanobacterial bloom in Malaysia. 


\section{ACKNOWLEDGEMENTS}

The authors are grateful to Universiti Sains Malaysia for providing financial assistance through Research University Grant Individual (RUI) (Grant number 1001.PTEKIND.811253) and Ministry of Education Malaysia (MOE) on Exploratory Research Grant Scheme (ERGS) (Grant number 203. PTEKIND.6730135) for this work.

\section{REFERENCES}

[1] WHO, Toxic cyanobacteria in Water: A guide to their public health consequences, monitoring and management. 1999, London: E \& FN Spon.

[2] Codd, G., et al., Cyanobacterial toxins, exposure routes and human health. European Journal of Phycology, 1999. 34(4): p. 405-415.

[3] Mihali, T.K., et al., Characterization of the gene cluster responsible for cylindrospermopsin biosynthesis. Applied and environmental microbiology, 2008. 74(3): p. 716-22.

[4] Mahakhant, A., et al., Detection of microcystins from cyanobacterial water blooms in Thailand fresh water. Phycological Research, 1998. 46(2): p. 25-29.

[5] Te, S.H. and K.Y.H. Gin, The dynamics of cyanobacteria and microcystin production in a tropical reservoir of Singapore. Harmful Algae, 2011. 10(3): p. 319-329.

[6] Sinang, S.C., et al., Preliminary assessment of cyanobacteria diversity and toxic potential in ten freshwater lakes in Selangor, Malaysia. Bulletin of Environmental Contamination and Toxicology, 2015. 95(4): p. 542-7.

[7] Shao, J., et al., Potential for control of harmful cyanobacterial blooms using biologically derived substances: Problems and prospects. Journal of Environmental Management, 2013. 125(0): p. 149-155.

[8] $\mathrm{Ni}$, L., et al., Inhibitory effects of the extracts with different solvents from three compositae plants on cyanobacterium Microcystis aeruginosa. Science China Chemistry, 2011. 54(7): p. 1123-1129.

[9] Lalung, J., Molecular analysis of microbial involvement in the activation of barley straw for use in the control of Cyanobacterial growth, in Faculty of Biological Sciences2012, The University of Leeds. p. 227.

[10] Ridge, I., J. Walters, and M. Street, Algal growth control by terrestrial leaf litter: a realistic tool? Hydrobiologia, 1999. 395-396(0): p. 173-180.

[11] Zhang, C., et al., Algicidal activity and potential mechanisms of ginkgolic acids isolated from Ginkgo biloba exocarp on Microcystis aeruginosa. Journal of Applied Phycology, 2013. 26(1): p. 323-332.

[12] Park, M.H., et al., Screening of seventeen oak extracts for the growth inhibition of the cyanobacterium Microcystis aeruginosa Kütz em. Elenkin. Bulletin of Environmental Contamination and Toxicology, 2006. 77(1): p. 9-14.

[13] Yang, J.-D., et al., Lysis of Microcystis aeruginosa with extracts from Chinese medicinal herbs. International Journal of Molecular Sciences, 2009. 10(9): p. 4157-4167.

[14] Nakai, S., S.Yamada, and M. Hosomi, Anti-cyanobacterial fatty acids released from Myriophyllum spicatum. Hydrobiologia, 2005. 543(1): p. 71-78.

[15] Wu, X., et al., Study on the release routes of allelochemicals from Pistia stratiotes Linn., and its anti-cyanobacteria mechanisms on Microcystis aeruginosa. Environmental Science and Pollution Research, 2015. 22(23): p. 1-8.

[16] Zhang, T.T., et al., Inhibitory effects and mechanisms of Hydrilla verticillata (Linn.f.) Royle extracts on freshwater algae. Bulletin of Environmental Contamination and Toxicology, 2012. 88(3): p. 477-481.

[17] Ni, L.X., et al., Antioxidant and metabolism responses to polyphenol stress in cyanobacterium Microcystis aeruginosa. Journal of Environmental Science and Health. Part. B, Pesticides, Food Contaminants, and Agricultural Wastes, 2013. 48(2): p. 153-61.

[18] Gross, E.M., Allelopathy of aquatic autotrophs. Critical Reviews in Plant Sciences, 2003. 22(34): p. 313-339. 


\section{Tengku Nadiah Yusof et al.}

[19] Xiao, X., et al., A pair of chiral flavonolignans as novel anti-cyanobacterial allelochemicals derived from barley straw (Hordeum vulgare): characterization and comparison of their anticyanobacterial activities. Environmental Microbiology, 2014. 16(5): p. 1238-1251.

[20] Jianzhong, C., et al., Control of Microcystis aeruginosa TH01109 with batangas mandarin skin and dwarf banana peel. Water SA, 2004. 30(2): p. 279-282.

[21] Miller, Louis H. and X. Su, Artemisinin: Discovery from the Chinese herbal garden. Cell, 2011. 146(6): p. 855-858.

[22] Ni, L., et al., Isolation and identification of an anti-algal compound from Artemisia annua and mechanisms of inhibitory effect on algae. Chemosphere, 2012. 88(9): p. 1051-1057.

[23] Peng, S.L., J. Wen, and Q.F. Guo, Mechanism and active variety of allelochemicals. Acta Botanica Sinica, 2004. 46(7): p. 757-766.

[24] Van Apeldoorn, M.E., et al., Toxins of cyanobacteria. Molecular Nutrition \& Food Research, 2007. 51(1): p. 7-60.

[25] Baxa, D.V., et al., Estimating the abundance of toxic Microcystis in the San Francisco Estuary using quantitative real-time PCR. Harmful Algae, 2010. 9(3): p. 342-349. 